\title{
Valence and Atomic Number
}

\section{Daniel Harbour}

The semantic basis and morphosyntactic reflexes of Kiowa-Tanoan noun classification are perspicuously captured in a system with three bivalent number features: [ \pm singular], $[ \pm$ augmented], [ \pm group]. Privative analyses of the same facts require, inter alia, features without semantic motivation, syntactic mechanisms that violate Inclusivity, and feature annotation reminiscent of bivalence. The semantic atoms of number are, therefore, bivalent.

Keywords: bivalent, dual, features, inverse, noun classes, number, plural, privative, singular, Jemez, Kiowa, Kiowa-Tanoan

\section{Introduction}

Since its introduction by Jakobson, Karcevsky, and Trubetzkoy (1928), the feature has become the atomic mainstay not just of phonology, but also of morphology, syntax, and much of semantics. One of the chief distinctions to have arisen since its inception is that between privativity and bivalence (e.g., Noyer 1992 vs. Harley and Ritter 2002; see Adger and Harbour 2007b and below for further references). For instance, to express plurality, one could posit privative [F] or bivalent $[ \pm \mathrm{F}]$. In the bivalent variant, elements are interpreted as plural if they bear $[+\mathrm{F}]$ and as nonplural if they bear $[-\mathrm{F}]$. In the privative variant, elements are interpreted as plural if they bear $[\mathrm{F}]$; elements without the feature are taken to be nonplural (Harley and Ritter 2002) or to be compatible with either interpretation (Reinhart 2002).

Parsimony prefers privativity. First, if nonassertion of plurality is interpreted as assertion of nonplurality, then $[-\mathrm{F}]$ is redundant. Second, the phrase structure grammar for bivalent features is an extension of that for privative features, and so bivalence requires richer resources (Adger 2006). Third, privativity is notationally more constrained: bivalence permits the three-way distinction $\emptyset \sim[-\mathrm{F}] \sim[+\mathrm{F}]$, but privativity, only the two-way distinction $\emptyset \sim[\mathrm{F}]$. Moreover, privativity has been adopted in some recent influential work (Harley and Ritter 2002, Béjar 2003, Béjar and Rezac 2009).

This article argues, however, that privativity is too restrictive (as found in an early attempt to adopt thoroughgoing privativity; Silverstein 1986:188, 227-228). Linguistic theory requires

This article has greatly benefited from the attention given it by David Adger, Morris Halle, Orin Percus, Laurel J. Watkins, and two LI reviewers, one of whom, in particular, offered a level of criticism well beyond the call of duty. The argument mounted in the article stems from research originally undertaken in relation to my 2003 dissertation, and I take this opportunity to reiterate my thanks to Vincent Bointy, Georgia Dupoint, and Dorothy Kodaseet, all of whom are now, regrettably, deceased. Part of the work for this article was undertaken under the auspices of Project $\boldsymbol{\aleph}$ (Atomic Linguistic Elements of Phi), Sub-Project $\Omega$ (Theory of Atomic Valence), Arts and Humanities Research Council of the United Kingdom grant AH/G019274/1. I am grateful to all of the aforementioned in many different ways. 
features with the three-way distinction $\emptyset \sim[-\mathrm{F}] \sim[+\mathrm{F}]$ that only bivalence permits. This claim is based on Kiowa-Tanoan noun classification. Kiowa, the primary focus below, has nine morphologically distinct noun classes, recognizable by their agreement patterns across singular, dual, and plural. The classes are semantically coherent, picking out such core semantic properties as collective $\sim$ noncollective, count $\sim$ mass, and heterogeneous $\sim$ homogeneous plural. The language motivates three features on semantic grounds: two, [ \pm singular] and [ \pm augmented], generate the number categories singular, dual, plural; and the third, [ \pm group], characterizes the types of pluralities that nouns form. (Paraphrases are given later.)

(1) Feature definitions ${ }^{1}$

a. $[+$ singular $]=\lambda x[\operatorname{atom}(x)]$

b. $[+$ augmented $]=\lambda \mathrm{P} \cdot \lambda x: \mathrm{P}(x) \cdot \exists y[\mathrm{P}(y) \wedge y \sqsubset x]$

c. $[+$ group $]=\lambda \mathrm{P}:[+$ augmented $] . \lambda x: \mathrm{P}(x)[\mathrm{Q}$-atom $(x)]$

$(\mathrm{Q}$, a contextually supplied free variable over predicates)

(2) Ancillary definitions

a. Presupposition: " $\lambda z$ : $\phi$ " means that $\phi$ is a presupposition on $z$

b. Q-atom: $x$ is a Q-atom if, and only if, $\mathrm{Q}(x) \wedge \neg \exists y[\mathrm{Q}(y) \wedge y \sqsubset x]$

c. Feature negation: $[-\mathrm{F}]=\neg[+\mathrm{F}]$

Given the features' semantics, it is possible to assign to each of the nine noun classes a featurevalue combination corresponding to that class's semantic characteristic. Straightforward assumptions about the syntax of agreement are then sufficient to explain the agreement pattern that identifies the class. This result is significant because it provides a single explanation for each class's semantic and morphological structure.

The argument against privativity arises when we consider why Kiowa has only 9 morphologically distinct classes, when one could well expect up to 64. Nine appears an arbitrary assemblage. However, when one applies the account just sketched to all potentially class-defining featurevalue combinations, only 14 distinct classes emerge. Between them, Kiowa and its Tanoan relation Jemez exhaust all possibilities, and no related language attests others. Thus, the system predicts exactly the classes that exist.

In sum, then, the virtues of a bivalence-based account are (a) semantic, as well as morphological, well-foundedness; (b) use of standard syntactic mechanisms; (c) descriptive adequacy with respect to the inventory of noun classes; and (d) explanatory adequacy with respect to the inventory of noun classes.

If one attempts to change the features that Kiowa-Tanoan motivates from bivalent into privative ones, however, the class typology is lost. The system immediately undergenerates, contra (c). To recapture generative adequacy, one must complicate the feature inventory and the syntactic

\footnotetext{
${ }^{1}$ These definitions differ in some details from those given in Harbour 2007, for reasons discussed below. The feature [ \pm singular] is a different type from the other two, $\langle\mathrm{e}, \mathrm{t}\rangle$ rather than $\langle\langle\mathrm{e}, \mathrm{t}\rangle,\langle\mathrm{e}, \mathrm{t}\rangle\rangle$. They could be made type-identical by rewriting $[+\operatorname{singular}]$ as $\lambda \mathrm{P} . \lambda x: \mathrm{P}(x)[\operatorname{atom}(x)]$. The shorter formula is used here for readability.
} 
component. However, the semantics of the noun class system motivates no additions to the feature inventory, contra (a). Any such additions are hence for purely morphological purposes and therefore sacrifice the tight connection between semantics and morphology. And altering the syntactic mechanisms admits agreement classes that are unattested and so syntactic generality is compromised, contra (b), and accuracy lost, contra (d). A coherent picture of the system is possible only if we accept that the number features are binary.

The argument is presented in three stages. Section 2 uses Kiowa's number system and a subpart of its class system to motivate the three semantically contentful features. Section 3 presents the complete typology of noun classes permitted by these features. It shows that, between them, Kiowa and Jemez attest all of the agreement classes (section 3.1) and that there is a natural connection between the classifying features of each class and the semantics of the nouns subsumed (section 3.2). Section 4 defines three different notions of privativity and shows that none is capable of delivering as insightful an analysis of Kiowa-Tanoan noun classification as the bivalent system.

\section{Features: Cardinality, Inverse, Groups}

This section motivates three number features in the analysis of Kiowa nouns: [ \pm singular], [ \pm augmented], and [ \pm group]. Section 2.1 introduces the canonical Kiowa noun and the mnemonic system used for noun classification. Subsequent sections examine the two types of deviation from the canonical agreement pattern. Section 2.2 introduces the inverse, a simultaneously plural and antiplural number marking, characteristic of the Kiowa-Tanoan family. This reveals the existence of three further noun classes. Section 2.3 accounts for these by proposing an inventory of number features. The features occupy two DP-internal projections, Class and Number, which jointly value $\mathrm{D}$, generating the inverse and agreement patterns. Finally, section 2.4 examines grouphood, the second way in which nouns deviate from the canonical agreement pattern. The result is an account of the content and distribution of number features throughout the DP, the predictions of which are tested in section 3. (The theory described below is developed more fully in Harbour 2007 but departs from it in the treatment of [ \pm group $]$.)

\subsection{Basic Nouns}

Kiowa distinguishes three numbers: singular, dual, plural.

(3) X!óú Ø /ę /gya-dóó.

stone $3 \mathrm{~s} / 3 \mathrm{D} / 3 \mathrm{P}-$ be

'It's a stone/two stones/some stones.'

In (3), the noun is unmarked for number and the cardinality of its referent is straightforwardly revealed by the agreement prefix. ${ }^{2}$ Nouns that display such transparent number agreement are

\footnotetext{
${ }^{2}$ On the morphophonology of the agreement prefix, which is very complex, see Watkins 1984 or Harbour 2007. Kiowa nouns never inflect for case. Prefixes are notated as $x: y: z^{-}$, where $x$ is an agent; $y$, a recipient, source, experiencer, or possessor; and $z$, a patient or undergoer. Hence, $z$ - is the agreement prefix of an unaccusative; : $y: z$-, that of an unaccusative plus experiencer/possessor; and $x: z-$, that of a simple transitive.
} 
termed SDP nouns. The first letter in the mnemonic stands for the agreement type triggered when the referent is singular, the second for the agreement type when the referent is dual, and the third for the agreement type when the referent is plural. So, SDP nouns, like 'stone', trigger s-agreement in the singular, D-agreement in the dual, and P-agreement in the plural.

Few Kiowa nouns are as transparent as 'stone'. The majority differ from the canonical, cardinality-transparent pattern of number agreement in one of two ways. The first, addressed immediately below, concerns cases in which the noun is suffixed according to its number. The second, addressed in section 2.4, concerns grouphood. (It may be thought that, if few nouns are canonical, then the nomenclature is inapposite. However, as Corbett (2005:26) observes, " canonical instances . . . may well not be the most frequent,' and, besides, deviations from the canonical case are all highly systematic.)

\subsection{Inverse-Marked Nouns}

Some nouns, such as those in table 1, differ from SDP 'stone' in displaying number-sensitive suffixation. The unsuffixed forms agree as one would expect on the basis of SDP nouns:

(4) a. Sópíí Ø- dóó.

fish 3s-be

'It's a fish.'

b. Śx́íílk!ôn /áá ę- dóó.

singular $\Leftrightarrow$ S-agreement

fish /tomato/stick 3D-be

'It's two fish/tomatoes/sticks.' dual $\Leftrightarrow$ D-agreement

c. Áá gya-dóó.

stick 3P- be

'It's some sticks.'

plural $\Leftrightarrow$ P-agreement

However, none of the suffixed forms trigger the numerically expected agreement. Rather, they all have a special agreement form.

(5) Óópíídó/k! จุǫdo /ááds e- dóó.

fish.I /tomato.I/stick.I 3I-be

'It's some fish/a tomato/some tomatoes/a stick.'

Such agreement is opaque to number, occurring with the singular and plural, as in (5), and with the dual, as in (6).

\section{Table 1}

Number-dependent noun marking

\begin{tabular}{|c|c|c|c|}
\hline Noun & Singular & Dual & Plural \\
\hline 'fish' & ópíí & óppíí & óxpíí-dó \\
\hline 'tomato' & k!อ๊̣-do & k!ôn & k! ְ̣ว-do \\
\hline 'stick' & áá-do & áá & áá \\
\hline
\end{tabular}


(6) E-x!óígyá.

1I-fall.s/D.PF

'We two fell.'

This suffix is traditionally called the inverse; its proprietal agreement form will be called I-agreement. (Both have a variety of allomorphs; see Watkins 1984, Harbour 2007.)

We can describe the agreement behavior of these nouns by substituting I into the SDP mnemonic. For instance, sópít 'fish' is an SDI noun, as it triggers s-agreement in the singular, D-agreement in the dual, but I-agreement, together with inverse marking on the noun, in the plural. Similarly, given table $1, k ! \hat{n} n$ 'tomato' is an IDI noun, and áá 'stick', IDP.

\subsection{Mechanism of Inverse Marking}

2.3.1 Number Features To account for inverse marking, we must first adopt a particular view of number. The number categories, singular, dual, plural, are taken to be the compositions of the atomic features in table 2, rather than the correspondents of category-specific number features, [singular], [dual], [plural]. To achieve this, the following definitions are assumed:

(7) Definitions: $[ \pm$ singular $],[ \pm$ augmented $]$

a. $[+$ singular $]=\lambda x[\operatorname{atom}(x)]$

b. $[+$ augmented $]=\lambda \mathrm{P} \cdot \lambda x: \mathrm{P}(x) \cdot \exists y[\mathrm{P}(y) \wedge y \sqsubset x]$

The minus values are defined as the negation of the plus values. Intuitively, [+singular] combines with a predicate, such as 'fish', with standard lattice-theoretic denotation (Link 1983), and restricts its satisfaction to the atomic part of the lattice. Similarly, [+augmented] restricts the lattice associated with $\mathrm{P}$ to those elements that are the join of elements at least one of which satisfies P. As a feature bundle, they are interpreted iteratively.

(8) Feature bundle interpretation

$$
[ \pm \text { singular } \pm \text { augmented }](\mathrm{P})=[ \pm \text { augmented }]([ \pm \text { singular }](\mathrm{P}))
$$

So, for instance, $[-$ singular -augmented $](\mathrm{P})$ restricts the lattice associated with $\mathrm{P}$ to its nonatomic subpart, [-singular](P), and then to the subpart with no further nonatomic subparts, [-augmented]. (This equates to the dual because dyads are the only nonatomic elements of the lattice that themselves lack nonatomic subparts. See Harbour 2006, 2007 for full proofs of the correspondence

\section{Table 2}

Feature composition of cardinalities

\begin{tabular}{lll}
\hline Category & {$[ \pm$ singular $]$} & {$[ \pm$ augmented $]$} \\
\hline Singular & + & - \\
Dual & - & - \\
Plural & - & + \\
\hline
\end{tabular}


in table 2 and for the contradictority of [+singular +augmented]. $)^{3}$ See section 2.3 .3 for a more detailed sample derivation.

With these features in hand, we can proceed to the analysis of inverse marking and I-agreement.

2.3.2 Inverse Forms We account for inverse marking and I-agreement by associating with each noun, or noun class, a feature-value combination. As these combinations propagate through the syntax, they lead to conflicting feature specifications. Inverse forms, whether on the noun or on the verb, are the vocabularic reflex of such conflicts.

Assume, uncontroversially, that the unsuffixed form of the noun is basic. So, for SDI nouns, the S/D form is basic; for IDP, the D/P form; and for IDI, only the D form. We associate with each noun the number features that correspond to its basic form. So, for SDI nouns, the feature common to the basic forms, S/D, is the feature common to singular, [+singular -augmented], and dual, [-singular -augmented] - that is, [-augmented]. So, the class feature for SDI nouns is [-augmented]. By similar reasoning, we have the initial typology in table 3 (shown with example nouns).

Syntactically, I assume DPs to have the structure in (9).

(9)

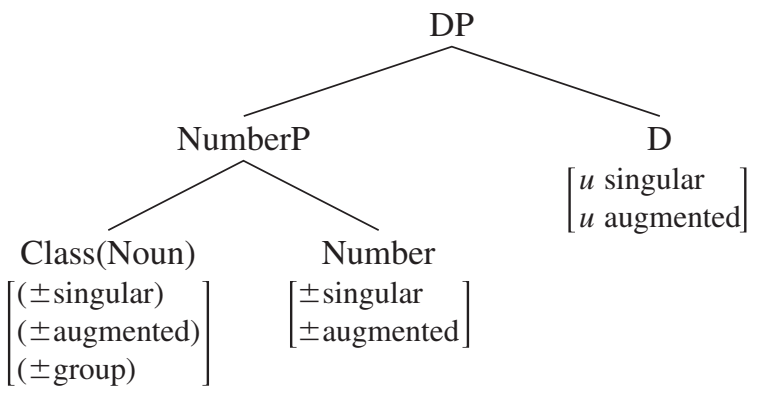

Table 3

Class features I

\begin{tabular}{lll}
\hline Class & Class features & Examples \\
\hline SDI & {$[$-augmented $]$} & '(wo)man', 'ant', 'knife', 'axe', 'sun', 'star' \\
IDP & {$[-$ singular $]$} & 'seed', 'grass', 'onion', 'bucket', 'dish' \\
IDI & {$[-$ singular - augmented $]$} & 'apple', 'plum', 'tomato', 'hair', 'eyebrow' \\
\hline
\end{tabular}

${ }^{3}$ If the order of composition in (8) is reversed, the set of distinctions that the features make collapses with that made by [ \pm augmented] alone. Informally, [ \pm augmented] divides the lattice corresponding to 'fish', say, into its atoms (elements without subelements that satisfy 'fish') and nonatoms. Further specification of [ \pm singular] picks out either the whole of the same region or nothing at all: for instance, $[+\operatorname{singular}]([-$ augmented $](\lambda x f i s h(x)))$ redundantly picks out all and only the atoms from the atomic stratum defined by [-augmented $](\lambda x \operatorname{fish}(x))$; and $[-\operatorname{singular}]([-\operatorname{augmented}](\lambda x$ $f i s h(x)))$ picks out all the nonatoms, of which there are none. So, if the order is the opposite of (8), then [ \pm singular] makes no contribution and fails to yield a system relevant to the analysis of Kiowa and Jemez. 
Number is the locus of the features that constitute singular, dual, and plural (e.g., Carstens 1991, Ritter 1991, 1993). These features are interpreted in accord with (7)-(8). Class is the categoryforming projection that attaches to the root to create a noun (Marantz 1997, Kihm 2002) —or, in Ouhalla's (2005) terminology, makes the root syntactically visible. This is the locus of the features in table 3. For the moment, we will treat these features as purely formal, that is, without semantic content, though we will see in section 3 that the features, even if model-theoretically inert, nonetheless are determined by the conceptual content of the head noun. Finally, D has number features (otherwise, there could be no number agreement, on the assumption that it is D that agrees with categories of the extended verb projection; e.g., Chomsky 2001). Not only are these features wholly without semantic import, they also have no value (notated $[u \mathrm{~F}]$ ) and must be valued in the syntax. It is the process of valuation, I argue, that gives rise to inverse marking and I-agreement.

Observe, first, that Class and Number must jointly value D: if only Number did, all nouns would be SDP, and if only Class did, nouns would agree invariantly for all numbers. In practical terms, I assume that this is possible because Class and Number are equidistant from D, as the lowest projections of the noun phrase (an approach developed at length in Harbour 2007:chaps. 3-4); however, the precise mechanism is not crucial to what follows. ${ }^{4}$

In cases where the feature content of Class is a subset of Number, it is trivial to value D: D replicates the feature content of the two. This is illustrated in (10) for the singular sDi noun śópí 'fish': Class is [-augmented], which is a subset of singular Number, [+singular -augmented]. All are straightforwardly replicable on $\mathrm{D}$, which then triggers s-agreement.

Issues of order of composition do not arise if one posits [singular], [dual], [plural]. Typical evidence against these simplistic features, in favor of more abstract ones, like those in the main text, comes from the dual (e.g., Noyer 1992, Hale 1997, Cowper 2005; see Harbour 2006 on other numbers). Observe that, in table 2, the dual is composed of elements of the singular and the plural. Similarly, in (ii), the dual is a transparent composition of singular (i) and plural (iii).
(i) X!óú-êl gya- ót.
stone-big.s 1s:3s-drop.s/D.PF
'I dropped a big stone.'
(ii) X!óú-bîn nen- ót.
stone-big.D/P 1s:3D-drop.s/D.PF
'I dropped two big stones.'

(iii) X!óú-bîn gyat- p!ét.

stone-big.D/P 1s:3P-drop.P.PF

'I dropped some big stones.'

'Big' and 'drop' supplete for number, and the dual shares the latter with singular and the former with plural. ('Big' in (i)-(iii) is a compounded form of the predicate 'be big', which agrees like any other, as in X!óú Ø-êt/ę-bîn/gya-bîn 'The stone/Two stones/Several stones is/are big'; cf. (3).) Table 2 readily accounts for (i)-(iii): if [ \pm singular] conditions $\hat{e} l \sim b \hat{\imath} n$, and if [ \pm augmented] conditions ót $\sim p ! e ́ t$, then we directly capture their distribution. Such evidence does not render the inventory $\{[$ singular], [dual], [plural] $\}$ impossible: [singular] might condition $\hat{e} l$, and [plural] p!ét, the others being elsewhere forms. However, see Harbour 2007:chap. 4 for evidence from incorporation and adverb formation that none is an elsewhere form. Also, this inventory would have difficulty with the inverse; see footnote 15 .

${ }^{4}$ Consequently, NumberP here must be identified with Borer's (2005) DivP, rather than her \#P. Given that Borer regards Div as the locus of plural inflection, it is, on current terms, the locus of number features; so, this identification seems straightforward. See Tsoulas 2009 for further comparison of these two approaches to number. (The symbol "\#”, is used by other authors to signify the locus of number features. See, for example, Harley and Ritter 2002, Béjar 2003.) 
(10)



However, Class is not always a subset of Number. For a plural SDI noun, for instance, Class is [-augmented], but Number is [-singular +augmented]. Under such circumstances, I claim the valuation of D proceeds identically, as shown in (11).

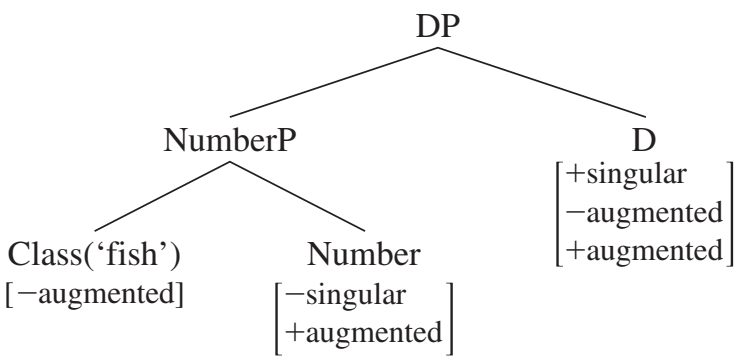

The crucial difference between this case and the previous one is the marked situation of having conflicting feature specifications on a single head, D. Semantically, this raises no issue because the only model-theoretically interpreted features are those under Number. Nonetheless, two comments are in order, concerning how conflict is syntactically possible and how it is morphologically realized. (See section 2.3.3 for more detail of the derivation of (10)-(11).)

Syntactically, unvalued features are generally assumed straightforwardly to lack values (Chomsky 2001). On this view, $u$ marks a lacuna: uninterpretable $[ \pm F]$ is $\left[\_F\right]$, which the syntactic algorithms map to $[+\mathrm{F}]$ or $[-\mathrm{F}]$. Consequently, there is no way to value $[u \mathrm{~F}]$ as $[-\mathrm{F}+\mathrm{F}]$, as occurs for [uaugmented] in (11). An extra $[u \mathrm{~F}]$ must be produced, violating Inclusivity. As this violation involves only copying, it may not disturb all readers. However, an alternative view is possible, according to which $[u \mathrm{~F}]$ abbreviates overspecification, with both values present on a single $\mathrm{X}^{0}$.

\section{(12) Valuation}

a. $[u \mathrm{~F}]$ abbreviates $[-\mathrm{F}+\mathrm{F}]$ : an uninterpretable instance of a feature consists of all value specifications of that feature.

b. Uninterpretable $[\alpha \mathrm{F}]$ is valued if, and only if, it is matched with an interpretable $[\alpha \mathrm{F}]$ in the appropriate domain.

c. A feature that has been matched is visible at PF. (Unmatched $[u \mathrm{~F}]$ features are invisible.) 
On this view, D bears [-singular + singular -augmented +augmented] when merged. In (10), D matches only [+singular -augmented], the other features delete, and D thus triggers P-agreement. In (11), D matches [-augmented] with Class and [-singular +augmented] with Number; so, D bears [-singular - augmented +augmented], a bundle with conflicting specifications of a single feature, without violating Inclusivity. (Recall that number features on D are semantically inert, so the meaning of these feature conflicts is not an issue. $)^{5}$

The morphological properties of this system are explored at length in Harbour 2007:chaps. 3-5. In brief, they are as follows. Conflict is realized as an inverse form.

\section{(13) Kiowa inverse}

$$
[-\mathrm{F}+\mathrm{F}] \Leftrightarrow \mathrm{I}
$$

As a vocabulary item, (13) is abstract in several important ways. First, no phonological content is given (see Watkins 1984, Harbour 2007 on the complex details). Rather, I is used as a phonological cover term. Second, (13) is silent about syntactic category. If $[-F+F]$ is located on $D$, the result is inverse marking, as in śxpút-dó 'fish-I'. ${ }^{6}$ If it is located on a head that D agrees with, the result is I-agreement, as in $e$-dós 'is/are' (3I-be). Third, (13) does not mention [ \pm augmented] specifically, even though (12) concerns the conflict [-augmented +augmented]. The generality in (13) permits us immediately to apply the account to IDP and IDI nouns. For IDP nouns, inverse marking will arise when Number bears a specification that conflicts with the classifying feature [-singular], that is, when Number is [+singular -augmented], or singular. And for IDI nouns, where Class is [-singular -augmented], conflicts will arise when Number is [+singular -augmented] or [-singular +augmented], that is, either singular or plural. For SDP nouns, we simply suppose that Class is empty, in which case D replicates Number, resulting in agreement that transparently reveals the number of the referent.

We have, therefore, proposed a two-feature inventory that generates the number categories of Kiowa and can be used to classify Kiowa nouns so as to explain, in conjunction with a simple statement about exponence of feature conflicts, the distribution of inverse marking on nouns and I-agreement on verbs.

\footnotetext{
${ }^{5}$ Discussion of the overspecification approach to uninterpretability lies beyond the scope of this article. See Harbour 2007:76-78 for brief examination and Harbour 2009b and 2011 for further evidence of cooccurrence of [ $-\mathrm{F}+\mathrm{F}]$. A reviewer asks whether overspecification amounts to an "extension of pure bivalent features" and an admission that the system requires more than the features argued for here. A simple response is that even if this is an extension of a more basic system, it is one that the Kiowa-Tanoan data suggest is necessary, and so one may judge the adequacy of a feature system according to whether it can accommodate this extension or not. However, a more sophisticated response is possible: in a combinatorial system, such as syntax, the default assumption is that posited entities may cooccur-the contrary assumption, forbidding cooccurrence, represents an extrinsic stipulation. Of course, independent constraints, such as semantic incompatibility, may rule cooccurrence out; however, semantic restrictions have no force when we are dealing with uninterpreted features. Consequently, a system of grammars with both $[+\mathrm{F}]$ and $[-\mathrm{F}]$ is, at least prima facie, simpler if it allows $[-\mathrm{F}+\mathrm{F}]$ than if it does not.

${ }^{6}$ For nonconflicting features, D is generally null. See Harbour 2007:chap. 2.
} 
2.3.3 Derivations I To round off, I will run through (10) and (11), explaining which features are pronounced and which are interpreted, that is, how the system thus far developed works as a whole. The mechanisms of syntactic valuation have already been discussed, so I will focus only on how these structures are treated in terms of pronunciation and interpretation.

The only parts of the tree that are pronounced are the head noun and, if (13) applies, D. Number is always silent. So, with vocabulary items, (10), [Class J́xpút [Number [D ]]], is pronounced simply as śxpít. The plural, (11), differs only in the application of (13) to D, which, in this case, calls for insertion of dó, resulting in [Class śópút [Number [D dó]]], pronounced as śópídó.

The parts of the tree that are interpreted are the head noun and Number. The number features on Class and D are model-theoretically inert. In the interests of space, I derive only the plural.

(14) NumberP》

$$
\begin{aligned}
& =\llbracket[- \text { singular +augmented }](\text { fish }) \rrbracket \\
& =\llbracket+\text { augmented } \rrbracket(\llbracket-\operatorname{singular} \rrbracket(\lambda x[\operatorname{fish}(x)])) \text { by (8) } \\
& =\llbracket+\operatorname{augmented} \rrbracket(\lambda x[\neg \operatorname{atom}(x)](\lambda x[\mathrm{fish}(x)])) \stackrel{\text { by }(1 \mathrm{a}),(2 \mathrm{c}) \text { and assuming }}{\neg \lambda x \mathrm{P}(x)=\lambda x \neg \mathrm{P}(x)} \\
& =\llbracket+\operatorname{augmented} \rrbracket(\lambda x[\neg \operatorname{atom}(x) \wedge \mathrm{fish}(x)])^{7} \begin{array}{l}
\text { by predicate } \\
\text { modification }
\end{array} \\
& =\lambda \mathrm{P} \cdot \lambda x: \mathrm{P}(x) \cdot \exists y[\mathrm{P}(y) \wedge y \sqsubset x](\lambda x[\neg \operatorname{atom}(x) \wedge \operatorname{fish}(x)]) \text { by (1b) } \\
& =\lambda x: \neg \operatorname{atom}(x) \wedge \operatorname{fish}(x) . \exists y[\neg \operatorname{atom}(y) \wedge \operatorname{fish}(y) \wedge y \sqsubset x] \begin{array}{l}
\text { by function } \\
\text { application }
\end{array}
\end{aligned}
$$

Formula (14) is satisfied by nonatomic fish (according to the presuppositional clause) that have subelements that are nonatomic fish (according to the nuclear clause). In other words, given that dyads are the only nonatomic elements that have only atomic subelements, the presupposition clause restricts $x$ to pluralities and the nuclear clause restricts $x$ to nondyads. Consequently, we have the plural. The interpretation of NumberP can then be further restricted by numerals, quantifiers, or the model-theoretically potent features within D, such as, possibly, [+definite] (see Adger, Harbour, and Watkins 2009:chap. 6 for discussion in the context of Kiowa; the topic lies beyond current scope).

\subsection{Grouphood}

2.4.1 The Feature We now turn to the second set of nouns that deviate from the canonical SDP agreement pattern. At the morphological level, these display s-agreement where P-agreement is expected and P-agreement where it is not expected. At the semantic level, they express types of grouphood: collective nouns in the former instance (15), or pluralia tantum nouns in the latter (16).

(15) Plural s-agreement

a. Phán Ø- dóó.

cloud 3s-be

'It's clouds.'

\footnotetext{
${ }^{7}$ If the alternative definition of $[ \pm$ singular $]$ is adopted (footnote 1 ), for type identity with $[ \pm$ augmented], then function application applies at this step, not predicate modification.
} 
b. Áá Ø- dóó.

tree $3 \mathrm{~s}$-be

'It's trees.'

(16) Nonplural P-agreement

a. Khóódé gya-dóó.

pants 3P- be

'It's one/two pants.'

b. Kút gya-dóó.

book 3P- be

'It's one/two books.'

The groupings are conceptually complementary. Collective nouns, such as spinneys of trees or banks of clouds, are singular-like when plural. They are pluralities without salient subparts. Pluralia tantum nouns are composite even when not plural (trousers are composed of legs and seats; books, of covers and leaves). They are pluralities with salient subparts.

The fact that we are dealing with complementary notions of grouphood suggests that these should be formalized as assertion and denial of a single concept. This is achieved by positing a single bivalent feature, $[ \pm$ group $]$.

(17) Definition: $[ \pm$ group $]$

$[+$ group $]=\lambda \mathrm{P}:[+$ augmented $] \cdot \lambda x: \mathrm{P}(x)[\mathrm{Q}-\operatorname{atom}(x)]$

[ \pm group] is restricted to augmented parts of lattices, that is, to elements composed of parts, and it is used to signify whether those parts are salient or nonsalient. For spinneys or cloud banks, the plurality is perceived as an individual, without salient parts. For pants and books, the individual is perceived as a plurality, with salient parts. Following a reviewer's suggestion (and in improvement over Harbour 2007; cf. the relationship between possessor and possessee in Partee and Borschev 2003), Q is treated as a contextually supplied, open variable: as the relevant collective noun in (15) and as the heterogeneous parts in (16). (For a measure of the degree of how dependent Q can be on extralinguistic, cultural/encyclopedic knowledge, see Ojeda 1998 on noun classification in Tohono O'odham, formerly known as Papago.) The formal compositional details of this feature's semantics can, however, be left aside: if we locate [ \pm group] under Class, then, like the previous Class features, it expresses part of the conceptual content of the root noun and so, though syntactically visible, its interpretation is subsumed by that of the noun and it is model-theoretically inert. However, we should not lose sight of the fact that the formal definition captures the two complementary notions of grouphood in the previous paragraph as a single bivalent feature. ${ }^{8}$

\footnotetext{
${ }^{8}$ For a compositional account, [ \pm group] induces a new lattice-like structure from the old one; compare the PL feature of Chierchia 1998. For [+group], the induced structure is that generated by collective (e.g., if the P-atoms are $\{a, b, c, d, e, f, \ldots\}$, then the Q-atoms are $\{a b c, a b d, \ldots, a b c d, \ldots\})$. For [-group], the structure is that generated by taking the heterogeneous parts (e.g., legs and seat, or covers and leaves) as atoms. In both cases, joins of Q-atoms are probably subject to well-formedness conditions, for which reason the structures are not lattices (e.g., for the collectives,
} 
A separate issue concerns the syntax of [ \pm group]. Descriptively, we need to say that the feature, when [+augmented] is present, overrides the usual valuation process (simple copying of [ \pm singular] and [ \pm augmented] from Class and Number) and instead causes D to be valued as though agreeing with a single spinney or bank or with a plurality of legs and seats or covers and leaves. That is:

\section{(18) Effect of $[ \pm$ group $]$ on valuation of $D$}

a. In presence of [+augmented], [+group] causes D to be valued as [+singular -augmented] (i.e., as a singularity).

b. In presence of [+augmented], [-group] causes D to be valued as [-singular +augmented] (i.e., as a plurality).

c. In absence of [+augmented], [ \pm group] is inert.

Naively drawing (19)/(20) for (15a)/(16a), respectively, with the previously established feature specifications for Number and D, we have: ${ }^{9}$

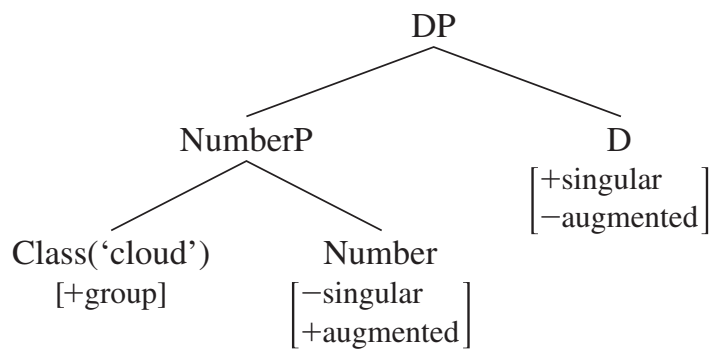

the join is defined only if the corresponding P-pluralities are disjoint, making $a b c \sqcup$ def well defined, but $a b c \sqcup a b d$ not). The number features that determine the value of $\mathrm{D}$ also indicate which level (atomic vs. nonatomic) of this new structure is accessed: the atomic level in the case of collectives, the nonatomic in the case of pluralia tantum. (Where the Q-atoms are collectives, whether the joins are accessible is, I assume, a matter of parametric/lexical variation. Kiowa appears to allow this only for some IDI nouns, such as 'different sorts of apples/hair'; see Watkins 1984:88-89, Harbour 2007:44. The Arabic plural-of-plurals, as in rijaal-aat 'collections of men' (man.PL-PL), described for example in Ojeda 1992, may represent the same phenomenon.)

${ }_{9}^{9}$ Observe that [+ augmented] is specified on Class in (20): it is absent from Number for reasons of cardinality (table 2 ) and, if absent from Class too, would not affect agreement in (16a). Hence its position. When there is no [+augmented] element for [ \pm group] to "predicate" of, it is uninterpreted and computationally inert and D is valued by copying, as though [ \pm group] were absent, as in (i).

(i)

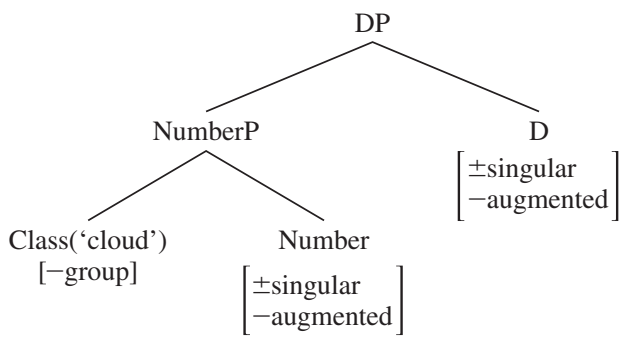


(20)

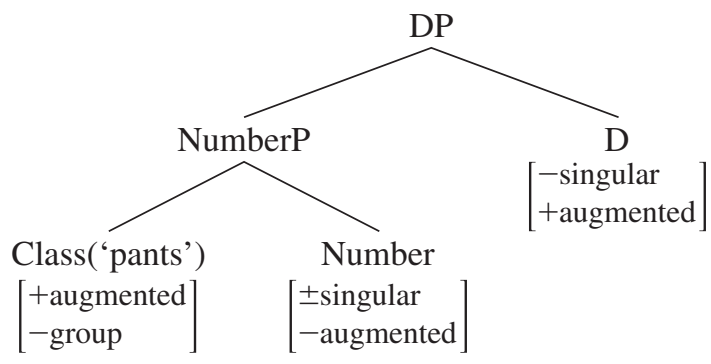

The question is what kind of mechanism allows D to be valued in this exceptional way. A useful analogy for the treatment of these nouns is the phenomenon of reference transfer.

(21) The hash browns at table six is/*are getting angry.

'The person at table six, who ordered hash browns, is getting angry.'

The point of such examples is that an internally plural phrase agrees and refers as though singular. Dowty and Jacobson (1988) and Pollard and Sag (1994), among others, use such examples to argue that agreement is essentially semantic, concerned with referents rather than syntactically specified features. It is hard to reconcile this position with the treatment of inverse marking and agreement above, according to which the inverse does not have a semantics and so cannot be semantically tracked. And it is unattractive to attenuate the claim to make agreement sometimes semantic, sometimes syntactic. Alternatively, though, one might suppose that sentences like (21) involve a covert dummy noun, meaning 'person', and that this is what is agrees with. This could be adapted to deal with the Kiowa cases, with the dummy noun being 'Q-atom'. Whichever mechanism one ultimately believes to be responsible for this phenomenon, the claim would be that [ \pm group] marks the set of nouns for which the mechanism is used obligatorily in Kiowa.

That said, it is important to reiterate that the syntactic mechanism is not the primary concern here. It is rather that there are complementary semantic properties, suggestive of a bivalent feature, that characterize nouns like those in (15)-(16). With this conceptual distinction in place, we can expand the typology of noun classes and their classifying features to table 4 (again, example nouns are given).

Table 4

Class features II

\begin{tabular}{lll}
\hline Class & Class features & Examples \\
\hline SDP & $\emptyset$ & 'shoe', 'boot', 'rock', 'key' \\
SDI & {$[$-augmented $]$} & '(wo)man', 'ant', 'knife', 'axe', 'sun', 'star' \\
IDP & {$[-$ singular $]$} & 'seed', 'grass', 'onion', 'bucket', 'dish' \\
IDI & [-singular -augmented] & 'apple', 'plum', 'tomato', 'hair', 'eyebrow' \\
SDS & [+group] & 'cloud', 'lake', 'river', 'road' \\
PPP & [+augmented - group] & 'pants', 'shirt', 'book' \\
\hline
\end{tabular}


2.4.2 Derivation II Little need be said about the derivation of the nouns just discussed. The syntax has been sketched and the morphological and semantic details are much as in section 2.3.3. In slightly more detail, in terms of pronunciation, all [ \pm group] does is induce singular or plural features on D where valuation by copying alone would not. However, as these features on D generally have no pronunciation, they do not affect how the noun is pronounced (their effect is pronounced only in the agreement system). So, all that is pronounced in these cases is the root noun, making these cases parallel to (10). And in terms of interpretation, all features are ignored except those under Number, given the treatment of Class as model-theoretically inert. Thus, the plural (20) is interpreted like (11), that is, as per (14), with the fact that these plurals form singularlike collectives constituting merely part of the speaker's encyclopedic knowledge of the object in question. (The singular in (21) is interpreted like (10).)

\section{Complete Typology of Noun Classes}

We are now in a position to prove an extremely interesting result, one crucial to the comparison of bivalence and privativity: that Kiowa almost optimally exploits the space of noun classes available to it. This result emerges from the need to cure the inventory of classes in table 4 of the apparent arbitrariness it acquires when we ask what constitutes a possible noun class in Kiowa. The issue is that some classes have one classifying feature, some two, some none. Some use positive values, some negative. No feature is common to all. If we consider that noun classes are recognized on the basis of the agreement types, S/D/P/I, used for singular, dual, and plural, we would expect $4^{3}=64$ different classes. The 6 in the table make up an apparently arbitrary subset.

However, when we begin to examine the typology that the account developed above permits, we discover three important facts:

(22) Important facts

a. Only a small number of morphologically distinct classes, 14, is generable.

b. All and only the generable agreement classes are attested (most, though not all, in Kiowa).

c. There is a semantically natural connection between each classifying feature set and the nouns the class subsumes.

This section proves these three results. By the end of the section, we will therefore have an inventory of bivalent number features that perfectly generates the attested number-based noun classes. This will place us in a position to examine, in the final section, whether the same results are replicable privatively. The section also discusses the difference between Kiowa-Tanoan and Indo-European noun classification and justifies the claim that class features express part of the conceptual content of the head noun. (An extremely preliminary sketch of these results was presented in Harbour 2007:112-113, with mention, rather than actual analysis, of Jemez.)

\subsection{Possible Classes}

Kiowa uses three features for noun classification, and these may be specified as absent, as plus, or as minus (as is [ \pm group] for IDI, SDS, and PPP, respectively; table 4). The possible classes are 
laid out in table $5 .^{10}$ Many distinct feature specifications yield nouns with identical agreement profiles, so that, in fact, only five classes emerge that were not attested above: SII, SIP, SSS, IDS, IIP. Interestingly, all exist.

Áá 'tree', mentioned above, is in fact an IDs noun; see (23). Thóúólkhóí 'whisky' is sss; see (24).

(23)
a. Áá- do e- dóó.
tree-I 3I-be
'It's a tree.'
b. Áá ę- dóó.
tree 3D-be
'It's two trees.'
c. Áá Ø- dóó.
tree $3 \mathrm{~s}$-be
'It's some trees.'

\section{Table 5}

Typology of classes: Bivalent features

\begin{tabular}{llll}
\hline$[ \pm$ singular $]$ & {$[ \pm$ augmented $]$} & {$[ \pm$ group $]$} & Class \\
\hline+ & - & 0 & $S I I$ \\
+ & 0 & + & $S I S$ \\
+ & 0 & - & $S I P$ \\
+ & 0 & 0 & $S I I$ \\
- & + & + & $S S S$ \\
- & + & - & PPP \\
- & + & 0 & $I I P$ \\
- & - & 0 & IDI \\
- & 0 & + & $I D S$ \\
- & 0 & - & IDP \\
- & 0 & 0 & IDP \\
0 & + & + & $S S S$ \\
0 & + & - & PPP \\
0 & + & 0 & $I I P$ \\
0 & - & 0 & SDI \\
0 & 0 & + & SDS \\
0 & 0 & - & SDP \\
0 & 0 & 0 & SDP \\
\hline
\end{tabular}

${ }^{10}$ The table systematically excludes [-augmented \pm group], [+singular + augmented], and $[-\mathrm{F}+\mathrm{F}]$. The reason is that, as discussed in section 3.2, Class encodes properties of the head noun. To have a noun class defined by [ $-\mathrm{F}+\mathrm{F}]$, say, would be to claim that there are nouns characterized by both having and lacking the property denoted by $[ \pm F]$. By parity of reasoning, the contradictory specification [+ singular + augmented] is not a possible value of Class; and [-augmented \pm group] is also suspect, given that [ \pm group] "predicates" of [+augmented]. That said, it is easily checked that their inclusion results in no mnemonics beyond those in table 4, so the exclusion is an innocent simplification. (See also footnote 12.) 
(24) a. Thợúcolkhóí Ø- dóó.

whisky 3s-be

'It's whisky.'

b. Yíi thơućólkhóí gya- thóm.

two whisky 1s:3s-drink.PF

'I drank two whiskies.'

c. Phạaáo thơućólkhóí gya- thóm.

three whisky 1s:3s-drink.PF

'I drank three whiskies.'

In Kiowa, the sII class consists of a single item, the first person. Demonstrating its existence requires close attention to exponence and syncretisms that would take us too far afield (see Harbour 2007:chaps. 3, 5). It is simpler to observe that the class is common in Jemez (Noyer 1992, Sprott 1992, Yumitani 1998).

(25) Jemez sII class

(Yumitani 1998:120)

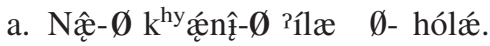

that- $\emptyset$ dog- $\emptyset$ much 3s-heavy

'That dog is heavy.'

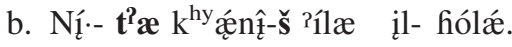

that-I dog- I much 3D-heavy

'Those [two] dogs are heavy.'

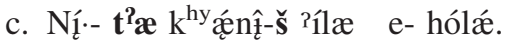

that-I dog- I much 3I-heavy

'Those [several] dogs are heavy.'

Inverse marking on the noun and demonstrative illustrates the sII pattern.

In contrast to verb agreement in Kiowa, Jemez verb agreement is not invariant under inverse marking: inverse-marked nouns occur with 3D $i l$ - and 3i $e$ - in (25). However, D- and I-agreement do frequently syncretize, as in (27a). To capture this, I suggest that the Jemez inverse is different from that of Kiowa (13).

(26) Jemez inverse

$[\alpha \mathrm{F} \alpha \mathrm{G}] \Leftrightarrow \mathrm{I}$

This causes inverse marking whenever two number features have the same sign. So, dual nouns will always be inverse-marked, as will the singular of any noun classed [+augmented]/[-singular], and the plural of any noun classed [+singular]/[-augmented]. The dual, [-singular -augmented], is a special case of (26); so, D-agreement, if it exists, will emerge over I-agreement, by Pānini's principle ([-singular -augmented] is more specific than $[\alpha \mathrm{F} \alpha \mathrm{G}])$. Where no D-specific agreement exists, however, dual and inverse will syncretize, as desired.

Two further agreement classes are made possible by (26): IIS, corresponding to [-singular +group], and III, corresponding to [-singular -augmented] (IDS and IDI in Kiowa). They, and the remaining classes, IIP, SIP, and SIS, are entirely unattested in Kiowa, but are, again, present in 
Jemez. In (27), inverse marking and I-agreement occur for 'one/two boxes', but P-agreement and an unmarked noun occur in the plural. So, 'box' is an IIP noun.

(27) Jemez IIP class

(Yumitani 1998:126)

a. Nị́- $\mathbf{t}^{2} \mathfrak{x} \mathrm{t}^{\mathrm{y}} \hat{\mathrm{e}} \cdot \mathrm{tib} æ-\mathbf{s}$ nị́

that-I box- I I :1s:3I-lie.s/D

'That box is mine.'

'Those [two] boxes are mine.'



that- $\emptyset$ box- $\emptyset$ I :1s:3P-lie.P

'Those [several] boxes are mine.'

'Bread', by contrast, is an sIs noun: unmarked and with s-agreement for one/many loaves, but inverse-marked for the dual. (The verb 'fall' suppletes for number, distinguishing the plural from the singular despite the presence of s-agreement in both. See Harbour 2007:chap. 4 for analysis of agreement $\sim$ suppletion mismatches in Kiowa; also see footnote 3.)

(28) Jemez sis class

(Yumitani 1998:100)

a. Bélá- Ø Ø- ší.

bread- $\emptyset$ 3s-fall.s/D

'A loaf of bread fell off.'

b. Bélǽ-š ịl- ší.

bread-I 3D-fall.s/D

'[Two] loaves of bread fell off.'

c. Bélá- Ø Ø- tí.

bread- $\emptyset$ 3s-fall.P

'[Several] loaves of bread fell off.'

Jemez SIS nouns appear in general to permit P-agreement, as an alternative to s-agreement, in the plural. For example:

(29) Jemez SIS $\sim$ SIP variation ${ }^{11}$

(Sprott 1992:91)

a. Béla ta- há.

bread 1s:3s-bake

'I baked bread.' [a coherent collection]

b. Béla tul- há.

bread 1s:3P-bake

'I baked bread.' [distributed individuals]

The difference between s-agreement and P-agreement in the plural is reminiscent of collective versus noncollective plurals in Kiowa: Sprott (1992:90ff.) characterizes P-agreement as correlating

${ }^{11}$ Sprott's and Yumitani's differing orthographies have been retained. 
with " being less concentrated, more diffuse, more spread out, and less identifiable as a collectivity or set.' In discussing (29), he notes that one informant is inclined to think of loaves of bread for (29a) versus tortillas for (29b), “Because when you're done with oven bread you have those breads sitting on the counter, but with tortillas it's just a stack.' Discussing the same alternation for hwúúla 'hair', Sprott says that P-agreement "fits a barber shop scene where the hair on the floor is of different colors," whereas, for s-agreement, the hair "came from a single person." Strictly speaking, then, sis is a subclass of SIP, with an optional [+group] specification. The situation constitutes only a minor divergence from the typology in table 5.

Finally, Sprott (1992:281) gives súiú(sh) 'rain' and tyúúwesh 'salt' as III nouns; similarly, p?ǽ 'water' and gahwé 'coffee' are sss, and tyứ 'grass' and hú 'clothes' are ppp. (Yumitani (1998:113) describes several different classifications for his speakers. Such discrepancies are not confined to these nouns and may be explained by generational change; see Sprott 1992:55-56, Yumitani 1998:7.)

Therefore, the validity of (22a) has been demonstrated: despite there seeming to be 64 mnemonically possible classes, the number that in fact exists is small, 14 to be precise. Moreover, to my knowledge, all descriptions of Kiowa-Tanoan languages report only the classes in table 5, or dualless or (26)-related variants thereof (see especially Noyer 1992 for references and comparative discussion, and Sprott 1989 for thorough references). Consequently, the account permits all and only the attested agreement classes. We now turn to the final claim that is important before we compare the bivalent analysis above with privative variants.

\subsection{Semantic Naturalness}

The final claim to be justified is that classes pick out semantically natural groupings of nouns and that there is a conceptually natural connection between the classifying feature of each class and the semantic characteristic of the nouns it subsumes. This will (further) justify the use of

\section{Table 6}

Kiowa noun classes

\begin{tabular}{|c|c|c|}
\hline Class & Class features & Semantic characteristics \\
\hline SDP & $\emptyset$ & default \\
\hline SII & [+singular] & first person only \\
\hline SDI & {$[$-augmented $]$} & independently mobile objects \\
\hline IDP & {$[-$ singular $]$} & $\begin{array}{l}\text { vegetation; most non-SDI implements; most } \\
\text { non-SDI body parts }\end{array}$ \\
\hline IDS & {$[-$ singular + group $]$} & $\begin{array}{l}\text { vegetation occurring in natural collections; } \\
\text { implements that may act collectively }\end{array}$ \\
\hline IDI & [-singular - augmented] & hair types; midsize fruit growing in clusters \\
\hline SDS & {$[+$ group $]$} & non-shape-inductive objects \\
\hline SSS & [+augmented +group] & nongranular mass nouns \\
\hline PPP & [+augmented - group] & $\begin{array}{l}\text { pluralia tantum nouns; granular mass nouns } \\
\text { (for some speakers) }\end{array}$ \\
\hline
\end{tabular}


semantically contentful features, rather than abstract gender features, in the characterization of the classes. The discussion concludes with some observations on the semantics of Class and the nature of Kiowa-Tanoan noun classification in crosslinguistic perspective.

3.2.1 Kiowa The classes attested in Kiowa are listed in table 6. The discussion of their semantic naturalness follows Harbour 2007, which synthesizes and expands on the insights of several authors, most especially Merrifield (1959), Takahashi (1984), and Watkins (1984).

SII is clearly a natural class, as it has only one element, and the connection between its member (the first person) and singularity is obvious (see Cysouw 2003 for conceptual and typological discussion).

The SDI class comprises all independently mobile objects. This includes all animates, such as people and animals (but not herds), mobile heavenly bodies such as the sun and moon, contraptions such as cars and wagons, cutting implements such as knives and scissors, and body parts capable of independent motion such as limbs, eyes, and articulated tails. Now, [+augmented] ensures that properties of the group are properties of the subgroup; that is, it ensures homogeneity. Conversely, then, [-augmented] is a measure of nonhomogeneity. As independence of motion is one correlate of nonhomogeneity, there is a natural nexus between SDI's class feature, [-augmented], and its defining characteristic, independent mobility.

Nouns denoting vegetation fall into one of three classes: IDP, IDS, or IDI. All are [-singular ( . . ) ]. Given the inherent connection between atomicity and individuality, this amounts, reasonably enough, to viewing vegetation as inherently nonindividual (one does not generally name trees in the way that one names human individuals, for instance). The same line of thought is carried over to non-SDI implements and body parts. Thus, most solid objects, such as animals, vegetables, and implements, are treated in one of two complementary ways: the independently mobile, individual-like ones are [-augmented] and the immobile, non-individual-like ones are [-singular].

For some immobile objects, the classification ends there. They are IDP. For those that form collective or collectively acting pluralities, such as spinneys and groves, or guns and cannons, or embers and lamps, the classifying feature [+group] is further added, giving IDS. For fruits that grow in nonhomogeneous clusters, with salient individuals, such as apples, plums, persimmons, and tomatoes, the feature [-augmented] is further added, giving IDI. The class also includes hair that grows in natural collections, such as head hair and eyebrows. These are simultaneously salient as component parts [-augmented] and as collections [-singular]. ${ }^{12}$

Non-shape-inductive objects (SDS) are things such as clouds, puddles, rivers, Westerners' houses. This class, like IDI, is small: it comprises objects that are clearly delineated but that can

\footnotetext{
${ }^{12}$ Considering the features separately is important. Unless we do so, the distribution of inverse marking on IDI nouns commits us to a specification of Class that essentially claims that these are conceptually inherently dual (the class features for this class are those that, under Number, yield the semantics of the dual). But hairs and tomatoes are not inherently dual, nor are salt and rain, the nouns with these class features in Jemez. Moreover, if features under Class are interpreted individually as applying to the head noun, then we are justified in excluding contradictory feature bundles from consideration in table 5; see footnote 10 .
} 
have quite varied shapes. Owing to such variation in shape, when several such objects are side by side, the boundaries of each are difficult to detect. Consequently, in pluralities, the individuals are not salient; rather, the plurality itself is. Hence, non-shape-inductive objects are [+group].

The connection between pluralia tantum nouns and [+augmented -group] was discussed above. The lack of class features for SDP and its status as a default is straightforward.

The final nouns to be discussed for Kiowa are mass nouns. All are [+augmented], capturing their well-noted plurisimilitude (Link 1983). They are subdivided into granular and nongranular, this difference being expressed by the feature [ \pm group], which measures salience of subparts. ${ }^{13}$ (I do not assume that all mass nouns in all languages are distinguished in this way; see Harbour 2009a, Tsoulas 2009.)

3.2.2 Jemez The same coherence apparently holds for Jemez (generalizing from examples and discussion in Sprott 1992, Yumitani 1998, and following also Noyer 1992); see table 7. Indeed, many classes are identical to those in Kiowa in terms of features and identical or nearly so in terms of semantic profiles: the featureless class is the default; [-augmented] is the class for animates; [-singular] is the class for vegetation, artifacts, and body parts. Similarly, granular and nongranular mass nouns constitute the same two classes in the two languages. Furthermore, the effect on agreement of [ \pm group] nouns correlates with the same semantic properties as in Kiowa: [+group] with a plurality forming a cohesive singular-like unit, [-group] with a singular item with salient components.

Nonetheless, there are some interesting differences between the two languages. Most obvious is the fact that the mnemonics corresponding to the featureless, [-augmented], and [-singular] classes are SDP, SDI, and IDP in Kiowa, but SIP, SII, and IIP in Jemez. This follows straightforwardly from the different inverse conditions operative in the two languages, (13) and (26), leading to inverse marking in the dual in Jemez but not in Kiowa.

\section{Table 7}

Jemez noun classes

\begin{tabular}{lll}
\hline Class & Class features & Semantic characteristics \\
\hline SIP & $\emptyset$ & default \\
SIS & {$[+$ group $]$} & collective counterpart of SIP \\
IIP & {$[-$ singular $]$} & vegetation; artifacts; body parts \\
IIS & {$[-$ singular + group $]$} & collective counterpart of IIP \\
SII & {$[-$ augmented $]$} & animates \\
SSS & {$[+$ augmented + group $]$} & nongranular mass nouns \\
III & {$[-$ singular - augmented $]$} & weakly granular mass nouns \\
PPP & {$[+$ augmented - group $]$} & granular mass nouns \\
\hline
\end{tabular}

\footnotetext{
${ }^{13}$ To motivate three-place cardinality-tracking mnemonics in the description of mass nouns, which are typically uncountable and so lack the cardinality that the mnemonics track, one can consider count-to-mass conversion or conjunction. See Harbour 2007:chap. 2.
} 
A more substantial difference concerns the inanimate nouns that are classmate with true animates in Kiowa. These include many motile objects, such as cars, stars, cutting implements, and various body parts, such as eyes and hearts. In Jemez, the class is more strictly animate, and the few inanimates it admits are closely related to animates, for instance, 'egg', 'corpse', and 'skeleton' (Sprott 1992:53-54). Sprott's rather brief lists suggest that inanimate sDI nouns are classed as defaults (SIP) in Jemez (viz., 'leg', 'tooth', 'sun', 'moon', 'star'). For Yumitani (1998), some of these (viz., 'moon', 'star') remain classmate with animates (as are 'pumpkin' and 'watermelon'); however, his lists confirm the tendency for Kiowa SDI inanimates to be SIP nouns in Jemez ('heart', 'axe', 'hammer', 'pocket knife'; words for 'doll' vary between the two across speakers). This correlation supports treating SIP as a featureless default (as against footnote 14, for instance): in diachronic terms, the addition or subtraction of a single feature is a smaller reclassification than the addition and subtraction of one or more. And, notwithstanding this reclassification around the margins, we should not lose sight of the fact that the semantic core of the [-augmented] class is the same in both languages and therefore that the explanation of the semantic nexus between class feature and semantic characteristics carries over from Kiowa to Jemez unaltered.

Similar considerations apply to the [-singular] class, which comprises vegetation, artifacts, and body parts in both languages. In consequence, the justification for correlation between feature and semantic characteristics again carries over. That said, both Sprott (1992:55-56) and Yumitani (1998:107) observe that it is hard to determine which vegetation, artifacts, and body parts are classed as IIP and which are default SIP. Sprott, in particular, notes a generational shift from IIP to SIP membership. However, without more information than is available, it is impossible to determine whether these developments are principled. Even if the shift turns out to be arbitrary, though, it would still be the case that there is a semantic nexus between feature and characteristic of the IIP class, even if that characteristic were merely a necessary, not sufficient, criterion of class membership.

The greatest difference between the two languages concerns the [-singular -augmented] class. As already noted, although this feature combination yields dual semantics if under Number, the nouns so classified are not inherently dual in either language, and the class features can only be understood as each individually encoding characteristics of the nouns they classify. In Jemez, Sprott (1992:96-97) found just two III nouns, sựứ(sh) 'rain' and tyúúwesh 'salt', which we can term "weakly granular,' as they occur in the natural but nonrobust units of drops and crystals. Like Kiowa IDI nouns, hair and certain fruit, these are also mass-like, occurring nonindividually (hence [-singular]) and yet having clear natural units (hence [-augmented]). Given that IDI and III nouns all share characteristics with other classes, it is unsurprising that their membership is nonconstant across the two languages. (That said, Yumitani (1998:109-110) notes that at least one Jemez speaker classes 'pear', 'cherry', and 'onion' as III nouns. None are IDI nouns in Kiowa, but, like the IDI foods, all are small to mid-sized and round, and they grow in clusters.) However, as for IIP versus SIP membership in the previous paragraph, the important point is whether there is a semantic nexus between class features and class characteristics, not whether those characteristics constitute necessary, rather than sufficient, conditions for class membership. 
On the above analysis, Kiowa and Jemez differ primarily with respect to the nature of inverse marking and agreement. The inventories of their noun classes are all but identical. A striking fact is that the cardinality features are used almost exclusively negatively (except for [+augmented], which cooccurs with [ \pm group], and for [+singular], for the first person, in Kiowa). However, relative to this restriction, the space of possible classes is almost optimally exploited by both languages individually, and is optimally exploited by the two languages jointly. ${ }^{14}$

3.2.3 The Semantics of Class In light of the foregoing discussion, it is useful to clarify the semantic nature of Class in Kiowa-Tanoan. The key point about noun classification in this family is its interaction with cardinality. This is accounted for by using number features for both Number and Class. However, as already emphasized, the interpretation of the features in these positions is not identical. Under Number, the features yield the cardinalities singular, dual, and plural; they affect the model-theoretic semantics. Under Class, they encode abstract properties of nouns, namely, their natural, or default, distribution in the real world; their semantics is subsumed by that of the head noun and so they behave as model-theoretically inert. The dual function of number features should not trouble us, however: if there are more concepts than features (Fodor 1977, Grimshaw 2005), then many-to-one relationships between concepts and the features that syntactically encode them may well result (see, e.g., Adger and Harbour 2007a on person features and Harbour 2011 on the relationship between number and aspect).

The resulting class system is distinct from that of Indo-European (though possibly similar to that of Bantu; see Harbour 2007:chap. 6). Consider, for instance, German Eiche 'oak'. This triggers the agreement typical of female things, such as Frau 'woman', Kellnerin 'waitress', and

\footnotetext{
primarily plus.

\begin{tabular}{|c|c|c|}
\hline Class & Class features & Semantic characteristics \\
\hline SIP & {$[+$ singular - group $]$} & default \\
\hline SIS & {$[+$ singular + group $]$} & collective counterpart to SIP \\
\hline IIP & {$[+$ augmented $]$} & vegetation; complex artifacts; body parts \\
\hline IIS & {$[$-augmented +group $]$} & collective counterpart to IIP \\
\hline SII & {$[+$ singular $]$} & animates \\
\hline sss & {$[+$ augmented + group $]$} & nongranular mass nouns \\
\hline III & {$[+$ singular +augmented $]$} & weakly granular mass nouns \\
\hline PPP & [+augmented - group] & granular mass nouns \\
\hline
\end{tabular}
}

${ }^{14}$ An alternative analysis is available in terms of positive class features (see table below). (This analysis is similar to Noyer's (1992), but avoids complications that arise in applying a Kiowa-like inverse condition to both languages. For instance, Noyer treats SIP as having Class $[-\mathrm{F}]$, thus triggering inverse whenever a feature is specified as plus; yet if we add $[ \pm$ group $]$ to the analysis (to deal with facts beyond Noyer's remit), the possibility that $[-\mathrm{F}]=[-$ group $]$ must be ruled out by stipulation.) The alternative below is curious in lacking (like Noyer's account) a default class, and questionable in the treatment it forces of III, IIS, and SIS. The class pairs IIS IIP and SIS SIP do not differ with regard to the same feature, as in table 7; rather, SIS $\sim$ SIP oppose for [ \pm group], and IIS IIP for [ \pm augmented]. Furthermore, the IIS combination [-augmented + group] is semantically odd, given that [ \pm group] "predicates" of [+augmented]. Semantic oddity also afflicts the treatment of III: if specified with plus values, it must be [+singular +augmented], which is contradictory (Harbour 2007). Either this contradictority must be accepted, or a lone minus classification, [-singular -augmented], must be retained from table 7 . Adopting this alternative analysis allows one to retain the optimal exploitation result, but an interesting difference emerges between the languages, as Noyer observes: Kiowa classifies using mostly minus; Jemez, 
Kuh 'cow'. Morphosyntactically, then, one requires Eiche to bear the same gender feature as Frau and the like. However, as oaks are not anatomically female, the gender feature must be semantically vacuous (as opposed to that of 'waitress'). This is what the notion of 'formal feature' (e.g., Corbett 2000) is intended to capture: morphosyntactically ert, model-theoretically inert.

However, this behavior, though reminiscent of Kiowa-Tanoan Class, is distinct from it: Kiowa-Tanoan class features, though they may be model-theoretically inert, are not conceptually so. They express part of the conceptual content of the nouns they classify. The German example in particular underscores this. Many tree names cluster in the feminine: Esche 'ash', Birke 'birch', Buche 'beech', Tanne 'pine', and so on. However, these could just as easily be masculine (der Esch, der Birk, etc.), as, indeed, Baum 'tree' itself is. In Kiowa, by contrast, the fact that one pine is not readily distinguishable from another means that these lack an important criterion of individuality and hence have the class feature [-singular]. (Forms of precipitation present a similar case. Hagel 'hail', Regen 'rain', Schnee 'snow', and so on, cluster in the masculine in German; however, they could equally well be neuter, as Wasser 'water' is. In Kiowa, forms of precipitation are conceived of as forms of water, with which they are, in consequence, classmate.) So, semantic clusters arise in particular classes for principled reasons rather than as accidents.

\section{Against Privativity}

We are now in a position to state the case against privativity: namely, that no privative recasting of the account offered above can preserve its virtues.

(30) Virtues of the bivalence-based account

a. All features are semantically motivated. None are mere morphological conveniences.

b. The syntactic mechanisms that generate inverse marking on nouns and I-agreement on verbs are nothing more than the mechanisms of agreement familiar from other languages.

c. The features generate all and only the attested agreement classes.

d. The features provide a clear explanation of why Kiowa and Jemez have the particular subsets of possible classes that they do.

To begin the argument, we distinguish three notions of privativity. We then apply them to the data discussed above.

\subsection{Types of Privativity}

In a binary feature system, there is a difference between $[+F],[-F]$, and absence of $[ \pm F]$. Consider, for instance, that the sII class has a positive specification for [ \pm singular]; the IDP class, a negative specification; and the SDP class, a zero specification. I take the hallmark of a privative feature system to be that only a two-way distinction is possible. This amounts to neutralizing the unmarked $\sim$ zero opposition, which can be achieved in two ways. One possibility is to define a new feature $\left[\mathrm{F}^{\prime}\right]$ corresponding to $[\alpha \mathrm{F}]$, with $[\bar{\alpha} \mathrm{F}]$ corresponding to zero. 


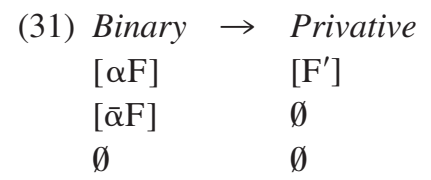

Let us call this presence absence privativity.

An alternative is to define a new two-valued feature $\left[ \pm \mathrm{F}^{\prime \prime}\right]$, with one value (say, plus) being the marked one, and the other being redundantly supplied (cf. Chomsky and Halle 1968).

$\begin{array}{lll}\text { (32) Binary } & \rightarrow & \text { Privative } \\ {[\alpha \mathrm{F}]} & {\left[+\mathrm{F}^{\prime \prime}\right]} \\ {[\bar{\alpha} \mathrm{F}]} & & {\left[-\mathrm{F}^{\prime \prime}\right]} \\ \emptyset & {\left[-\mathrm{F}^{\prime \prime}\right]}\end{array}$

Let us call this plus $\sim$ minus privativity.

A third possibility is to define two different features, corresponding to each of the values of $[ \pm \mathrm{F}]$.

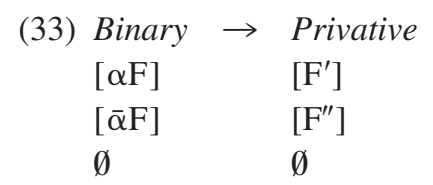

Although the resulting notation - features without values - is identical to the first option, it merely masks a three-way distinction, rather than disposing of it. It defeats the purpose of "going privative" by merely dressing up a binary distinction in the notation of privativity. I regard this as pseudoprivativity; nonetheless, I consider it briefly in section 4.4.

Neither presence $\sim$ absence nor plus $\sim$ minus privativity permits a three-way distinction between plus, minus, and zero. The fundamental difference between the two systems is that plus $\sim$ minus privativity permits reference to more natural classes than presence $\sim$ absence privativity does. $\{[-\mathrm{F}], \emptyset\}$, which is not a natural class in the binary system, is mapped onto a natural class, $\left\{\left[-\mathrm{F}^{\prime \prime}\right]\right\}$, in system (32), and so may be referred to by morphological rules and vocabulary items. This is not possible in presence absence privativity. Let us proceed with the latter, more restrictive option. (Pseudoprivativity does, of course, capture the natural classes of the bivalent analysis; however, it falls afoul of natural classes when it comes to the inverse.)

\subsection{Presence Absence Privativity}

4.2.1 Account We begin by positing two features, which I will simply call [F] and [G], that generate cardinalities as shown in (34).




(Clearly, [F] and [G] correspond to [-augmented] and [-singular], respectively.) ${ }^{15}$ This feature composition captures the composite nature of the dual (footnote 3 ) as well as the underlying classification of the Kiowa noun classes of sections 2.1 and 2.2: SDP is $\emptyset$, SDI is [F], IDP is [G], and IDI is [F G]. The challenge is to use these features to generate the other classes observed in Kiowa and Jemez. This involves specifying the featural content of Class and Number and the conditions under which they give rise to inverse marking and agreement.

However, generating inverse is not trivial. Above, it arose simply by copying cardinality features from Class and Number onto D and then spelling out the feature/value conflict, $[-\mathrm{F}$ $+\mathrm{F}$ ] for Kiowa, $[\alpha \mathrm{F} \alpha \mathrm{G}$ ] for Jemez, in a uniform fashion. With valueless features, such conflicts cannot arise. The only solution appears to be to suppose that the inverse is itself a value that D attains when Class and Number are in a specific relation. That is, we posit a feature [inverse] with the following property:

(35) Inverse by exclusion

$\mathrm{D}$ is valued as [inverse] when Class $\nsubseteq$ Number.

As an illustration, consider a singular or dual sDi noun. Class is $[F]$ and Number is $[F(G)]$. So, Class $\subseteq$ Number and the content of Number (and Class) is copied onto D, as shown in (36).

(36)

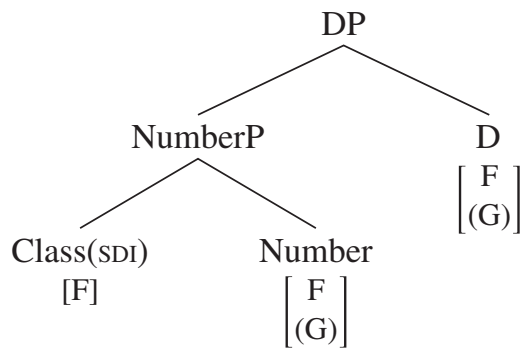

For the plural, however, Number is [G]. Copying alone, without (35), would value D as [F G], triggering D-agreement. However, given (35), and the obvious fact that Class $\not$ Number ([F] $\nsubseteq$ [G]), we have (37).

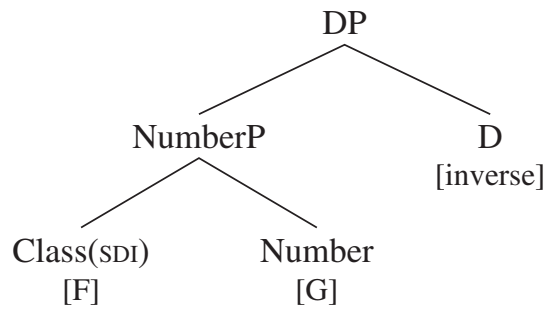

\footnotetext{
${ }^{15}$ The logical alternative of defining the numbers in terms of analogues of [+augmented] and [+singular] has the implausible consequence of correlating the marked number, dual, with the least marked, indeed empty, representation. See Nevins 2011 and Sauerland 2008 for recent discussion of the dual and its markedness. (In relation to footnote 3, observe that an inventory of undecomposed numbers, $\{$ [singular], [dual], [plural] $\}$, would lose all natural classes.)
} 
It is easily verified that (35) yields the correct inverse-marking and agreement types for SDP, IDP, and IDI nouns, given the classifications $\emptyset,[\mathrm{G}]$, and [F G].

The SDP, SDI, IDP, and IDI classes exhaust the possible classes generated by $\{[\mathrm{F}],[\mathrm{G}]\}$. To capture the SII class and others, then, a second inverse condition is required (discussion of the meaning and plausibility of these conditions, and of the feature [inverse], is deferred until section 4.2.2).

(38) Inverse by inequality

$\mathrm{D}$ is valued as [inverse] when Class $\neq$ Number.

For SII, we specify that Class is $[\mathrm{F}]$ and that D valuation is subject to (38). For the singular, Number is $[\mathrm{F}]$, therefore Class $=$ Number, and $\mathrm{D}$ is valued straightforwardly as $[\mathrm{F}]$. However, for the dual and plural, $[\mathrm{F}]=$ Class $\neq$ Number $=[(\mathrm{F}) \mathrm{G}]$. Consequently, (38) applies and D is valued as [inverse].

To capture the behavior of a class, then, we must specify both the content of the Class head and whether its inverse forms arise by exclusion (35) or by inequality (38). Even with the new feature and the two conditions, however, we still do not have descriptive adequacy, as nothing generates the SDS and PPP (pluralia tantum) classes.

In the bivalent account, SDS and PPP motivated the feature [ \pm group], both values of which were crucial and both distinct from absence of the feature. Unfortunately, we cannot posit a feature [gr] meaning the same as [+group] and a second feature [oup] meaning the same as [-group], as this is precisely the pseudoprivativity dismissed at the end of section 4.1. Moreover, having different features disguises the fact that we are dealing with the same basic semantic property: grouphood and its assertion or denial. However, if we introduce only one feature, one class is lost: without [gr] $=[+$ group $]$, there is no sDs; without [oup $]=[-$ group $]$, no PPP.

An alternative solution - the best I can devise without losing empirical coverage or positing novel, unmotivated features-is to introduce a diacritic on class features, which I will call ${ }^{x}$-notation. That is:

(39) Definition: ${ }^{x}$-notation

Let $[\mathrm{C}]$ be a feature on Class and $[\mathrm{N}]$, a feature combination on Number. Then:

a. $\left[\mathrm{C}^{x}\right] \stackrel{\subseteq}{=}[\mathrm{N}]$ if, and only if, $[\mathrm{C}] \subseteq[\mathrm{N}]$.

b. If $\left[\mathrm{C}^{x}\right] \stackrel{\subseteq}{\equiv}[\mathrm{N}]$, value(D) $=[\mathrm{N}]$. If $\left[\mathrm{C}^{x}\right] \underset{\nsubseteq}{\not}[\mathrm{N}]$, value(D) $=[\mathrm{C}]$.

Simply put, the notation permits D to be valued as Class in exactly those cases where it would normally be valued as [inverse]. Before I comment on this, let me illustrate how it works (again, evaluation of this approach is deferred until section 4.2.2).

The sDs class is $\left[\mathrm{F}^{x}\right]$, subject to inverse by exclusion. So, for singular or dual, D simply replicates Number: that is, (35) does not apply, because $[\mathrm{F}] \subseteq[\mathrm{F}(\mathrm{G})]$ and, so, Class $=\left[\mathrm{F}^{x}\right] \subseteq$ $[\mathrm{F}(\mathrm{G})]=$ Number. However, for the plural, given that $[\mathrm{F}] \not[\mathrm{G}]$, we have Class $=\left[\mathrm{F}^{x}\right] \nsubseteq[\mathrm{G}]$ $=$ Number. So, (35) applies. Ordinarily, this would value D as [inverse]. But, because of the ${ }^{x}$-notation on Class, $\left[\mathrm{F}^{x}\right], \mathrm{D}$ is valued instead as the class feature $[\mathrm{F}]$. Thus, we have s-agreement when plural. The result is SDS.

Using (39), it is possible to capture the PPP class, too: Class is $\left[\mathrm{G}^{x}\right]$, subject to inverse by inequality. So, the straightforward case is the plural: Number is $[G]$ and, given that $[G]=[G]$, 
it follows that Class $=\left[\mathrm{G}^{x}\right]=[\mathrm{G}]=$ Number; so, (38) does not apply and D is valued as [G]. However, for singular and dual, Class $\neq$ Number: $[\mathrm{G}] \neq[\mathrm{F}(\mathrm{G})]$, so $\left[\mathrm{G}^{x}\right] \neq[\mathrm{F}(\mathrm{G})]$. So, (38) applies. But, because of the ${ }^{x}$-notation on Class, $\left[\mathrm{G}^{x}\right], \mathrm{D}$ is valued instead as the class feature [G]. Thus, we have P-agreement for all numbers.

Let us finally consider IDS, the only class missing from a descriptively adequate account of Kiowa. A reasonable initial guess is to combine IDP and SDS: $\left[\mathrm{F}^{x} \mathrm{G}\right]$, subject to inverse by exclusion. However, (35) applies whenever Class $\nsubseteq$ Number, that is, whenever $\left[\mathrm{F}^{x} \mathrm{G}\right]$, or equivalently, $[\mathrm{F} \mathrm{G}] \nsubseteq$ Number. Thus, (35) applies for both singular and plural. By the definition of ${ }^{x}$-notation, $\mathrm{D}$ is valued in these cases as $[\mathrm{F}]$, resulting in sDs again.

To avoid this problem, we must relativize (35) so that "only problematic features count." That is, for singular, Number $=[\mathrm{F}]$ and the problematic feature is $[\mathrm{G}]$, not $\left[\mathrm{F}^{x}\right]$; so the latter is ignored and D is valued as [inverse]. Similarly, for plural, Number $=[G]$ and the problematic feature is $\left[\mathrm{F}^{x}\right]$; so $[\mathrm{G}]$ on Class is ignored, and D is valued as [F]. (IDI, [F G], functions as before.)

Assuming the revision in the previous paragraph, the valuation of $\mathrm{D}$ proceeds, in anthropomorphized summary, as follows:

(40) a. Momentarily ignore ${ }^{x}$-notation.

b. If Class $\subseteq$ Number, replicate Number on D.

c. If Class $\underset{\neq}{\not}$ Number, consider the problematic Class feature (i.e., the feature of Class, which, if removed, would ensure that Class $\subseteq$ Number). Value D in accord with that feature (i.e., as the feature if it is ${ }^{x}$-notated, as [inverse] otherwise). ${ }^{16}$

Consider the inventory of classes now generable. As shown in table 8, there are 18 possibilities, given the nine class features $\left[\left(\mathrm{F}^{(x)}\right)\left(\mathrm{G}^{(x)}\right)\right]$ and the two inverse conditions, (35) and (38). All Kiowa classes are generated. The Jemez classes SIP, SIS, and IIs, however, are not. Undergeneration

Table 8

Typology of classes: Privative features I

\begin{tabular}{lll}
\hline Class & $\begin{array}{l}\text { Inverse by } \\
\text { inequality }\end{array}$ & $\begin{array}{l}\text { Inverse by } \\
\text { exclusion }\end{array}$ \\
\hline$\emptyset$ & III & SDP \\
{$[\mathrm{F}]$} & SII & SDI \\
{$[\mathrm{G}]$} & IIP & IDP \\
{$[\mathrm{F} \mathrm{G}]$} & IDI & IDI \\
{$\left[\mathrm{F}^{x}\right]$} & SSS & SDS \\
{$\left[\mathrm{G}^{x}\right]$} & PPP & PDP \\
{$\left[\mathrm{F}^{x} \mathrm{G}\right]$} & IDS & IDS \\
{$\left[\mathrm{F} \mathrm{G}^{x}\right]$} & PDI & PDI \\
{$\left[\mathrm{F}^{x} \mathrm{G}^{x}\right]$} & PDS & PDS \\
\hline
\end{tabular}

${ }^{16}$ Talk of "the problematic feature" assumes that there is only one. This is true except on one occasion: when Class is empty, inverse by inequality applies, and Number $=[\mathrm{F} \mathrm{G}]$. In this case, D would be valued as [inverse]. 
can be repaired if inverse marking on Jemez nouns realizes not only [inverse], but also dual, [F G].

(41) Jemez inverse: Privative version [inverse $] /[\mathrm{F} \mathrm{G}] \Leftrightarrow \mathrm{I}$

Essentially, this maps D in (40) onto I, creating the missing mnemonics, SIP, SIS, and IIS, from SDP, SDS, and IDS. By recreating the effect of (26) in this way, we have a system that generates all the necessary noun classes.

With two systems, one bivalent and one privative, that generate the same set of noun classes, which is to be preferred?

4.2.2 Evaluation of Account The privative account possesses a certain elegance, I believe, as one and the same mechanism specifies both when $\mathrm{D}$ is not valued as [inverse], despite applicability of $(35) /(38)$, and how it is valued instead. It is, however, inferior in several regards.

First, the privative feature system overgenerates by $50 \%$. The following classes are predicted to be possible in Kiowa/Jemez: PDP/PIP, PDI/PII, PDS/PIS (table 8). All these arise from [G ${ }^{x}$, but ${ }^{x}$-notation cannot be restricted to $[\mathrm{F}]$ without loss of PPP. That these classes are not attested, and that, across the family, only two-thirds of possible classes are attested, makes the system, or the family, seem arbitrary.

Second, the privative system loosens the connection between feature semantics and noun class semantics. Great care was taken in the bivalent account to tie the features of each noun class to the semantic properties of the nouns that the class subsumes. Here, however, the contentful feature [ \pm group] has been replaced by ${ }^{x}$-notation. As the notation is a purely formal device, to which no meaning is assigned, there can be no correlation between it and the semantic characteristics of the nouns with which it is associated. Again, this makes the system as a whole appear somewhat arbitrary.

Third, the implications of ${ }^{x}$-notation are potentially problematic. It is not clear why language should permit it or even what such a device is: what other uses might language make of the formal underpinnings of ${ }^{x}$-notation? Moreover, one must wonder whether the introduction of

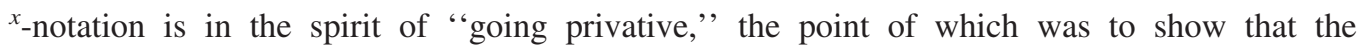
$\emptyset \sim[-\mathrm{F}] \sim[+\mathrm{F}]$ distinction permitted by bivalent features is superfluous. If we need compensatory devices, creating a new three-way distinction, $\emptyset \sim[\mathrm{F}] \sim\left[\mathrm{F}^{x}\right]$, then this suggests that privative features alone are too restrictive. Moreover, ${ }^{x}$-notation makes pure privativity seem too restrictive in a particularly suspicious fashion. The feature must be enriched by a form of diacritic notation. Given that "+", and "-," are themselves feature diacritics of a sort, ${ }^{x}$-notation points the way back to bivalence.

Fourth, the two different inverse conditions lack motivation and are quite questionable. If there is a tendency for vocabulary items to realize marked feature combinations (and, conversely, for zero to correlate with default specifications), then, for the bivalent system, the motivation for the existence of inverse forms is straightforward: in Kiowa, inverse is the vocabularic reflex of the marked situation in which feature values conflict; in Jemez, the marked situation in which the opposing features [ \pm singular] and [ \pm augmented] have nonopposing values. In the privative 
system, however, no such motivation is forthcoming. In fact, the whole concept of an inverse is unexpected, as feature conflicts cannot arise. They must be induced by principles such as (35) and (38). Consequently, on this account there is no natural motivation for one inverse, let alone two. Now, there is the interesting observation, concerning table 8 , that count nouns (modulo the first person) can be exclusively derived using (35) and mass nouns, using (38). However, it is impossible to capture this semantic partitioning of the two conditions so long as the conditions themselves lack semantic motivation.

Fifth, the idea of an [inverse] feature is itself problematic. The proposal has been made before (Noyer 1992, Harbour 2003), but it is clearly inferior to the bivalent approach pursued above. That account required only features that were semantically motivated. By contrast, [inverse] has no meaning: it arises purely in the course of syntactic computation, as a value of uninterpretable number on $\mathrm{D}$ and heads of the extended verbal projection. It is a mere morphological convenience. Moreover, [inverse] violates syntactic Inclusivity (Chomsky 2001): it is introduced to the syntax, not by Merge, but by computation, which therefore must do more than just match and copy.

Finally, to gain descriptive adequacy with regard to Jemez, a device to force syncretism between dual and inverse, (41), was required. Empirically, the idea is reasonable, as the two syncretize elsewhere in the language; contrast $(23 b-c)$ with (27a). However, implementation of this syncretism is opaque: [inverse] and [F G] are featurally disjoint, which ought to predict the impossibility of syncretism, unless their realization is an elsewhere form. However, this requires claiming that zero realization of $\mathrm{D}$, for singular, plural, and mass nouns, is more marked than inverse/dual marking. A similar problem holds for verbal agreement: Noyer (1992) argues that either s- or P-agreement is unmarked, and it is highly odd to regard the crosslinguistically marked dual and even more marked inverse as being, in fact, mere elsewhere forms. (The syncretism is straightforward in the bivalent system; see the discussion following (26). See also footnote 15.)

It is therefore fair to conclude that the bivalent account is syntactically more natural, semantically more insightful, and morphologically more constrained.

\subsection{Plus Minus Privativity}

Given the problems with presence $\sim$ absence privativity, it is reasonable to turn to the plus $\sim$ minus system. However, it is quickly shown that this system is descriptively inadequate. Let the bivalent features have privative correspondents $\left[ \pm\right.$ singular $\left.{ }^{\prime}\right],[ \pm$ augmented $]$, and $\left[ \pm\right.$ group $\left.^{\prime}\right]$. The DP is shown in (42).

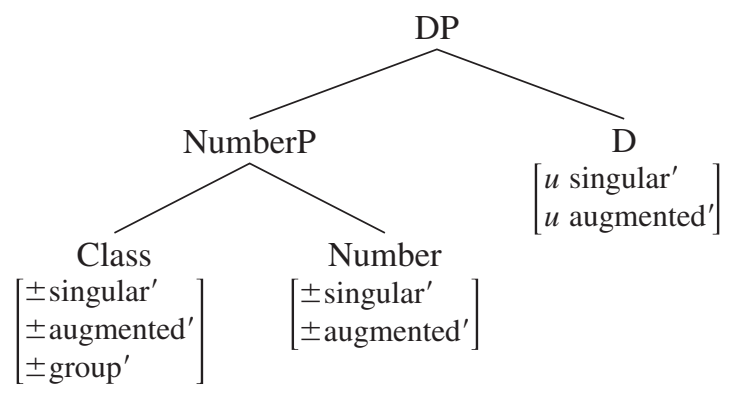


Zero specification, corresponding to the parentheses in (9), is not permitted. Allowing both the Kiowa and Jemez inverse conditions yields the 16 possibilities in table 9. Total absence of Class only generates 1 further class, SDP; and so, even permitting the semantically questionable [-augmented \pm group] and [+singular +augmented] in (42), there are not enough distinct classes: 10 falls 4 short. The only possibility is to enrich the system with further features and conditions concerning their effect on valuation of D. However, the semantic motivation of the features will be moot (as will be the naturalness of the conditions on valuation), given how neatly the features [ \pm singular], [ \pm augmented], and [ \pm group] correspond to the actual semantic properties of the numbers and noun classes that Kiowa-Tanoan presents.

\subsection{Pseudoprivativity}

As noted at the outset and signified by its name, pseudoprivativity is conceptually problematic, being bivalence in privative guise. Faced with the foregoing failures, however, one might be tempted to revisit it. So, it is worth briefly observing that it is also empirically problematic, when faced with the inverse.

To see this, suppose that [+singular] and [-singular] were represented as features [A] and $[B]$, and [+augmented] and [-augmented] as [C] and [D]. ${ }^{17}$ Then the Kiowa inverse, say, would arise whenever D bears [A B], or [C D], or any larger bundle containing these. However, as far as the morphology is concerned, these are just arbitrary feature combinations, and it would be just as plausible for the inverse to arise when D bears [A C] or [B D], that is, for singular and plural. The problem is that there is no way for morphology, which is in a different module from semantics, to "look inside" the features and "appreciate" that $[\mathrm{A}]$ and $[\mathrm{B}]$ are opposites, but

\section{Table 9}

Typology of classes: Privative features II

\begin{tabular}{|c|c|c|c|c|}
\hline \multicolumn{3}{|l|}{ Features } & \multicolumn{2}{|c|}{ Inverse } \\
\hline$\left[ \pm\right.$ singular $\left.{ }^{\prime}\right]$ & {$[ \pm$ augmented $]$} & {$\left[ \pm\right.$ group $\left.^{\prime}\right]$} & (13) & (26) \\
\hline+ & + & + & SSS & SSS \\
\hline+ & + & - & PPP & PPP \\
\hline+ & - & + & SIP & SIP \\
\hline+ & - & - & SIS & SIS \\
\hline- & + & + & SSS & SSS \\
\hline- & + & - & PPP & PPP \\
\hline- & - & + & IDP & IIP \\
\hline- & - & - & IDS & IIS \\
\hline
\end{tabular}

\footnotetext{
17 This sketch assumes presence $\sim$ absence privativity. Plus $\sim$ minus privativity would amount to positing $[ \pm \mathrm{A}]$ for $[+$ singular $]$ and $[ \pm \mathrm{B}]$ for $[-$ singular $]$, that is, two features for one semantic contrast, with $[ \pm \mathrm{A}]=[\mp \mathrm{B}]$. This duplication of information represents a clear loss of insight, and the analytic option is not taken further.
} 
that $[\mathrm{A}]$ and $[\mathrm{C}]$ are not; in a bivalent system, the complex nature of the symbols $[+\mathrm{F}]$ and $[-\mathrm{F}]$ enables precisely such comparisons.

As a possible way around this, one might suppose that the features on D yield the inverse whenever Class is not a subset of Number, mimicking the inverse by exclusion of (35). However, application of that principle here is problematic, for two reasons. First, (35) concerned syntactic valuation: the content of two heads determined the content of a third, with which they were in an Agree relation. The version to be adopted here, by contrast, concerns the pronunciation of that third head after the Agree relation has taken place, and, oddly, it claims that the content of that head is irrelevant to its pronunciation - rather, whether a subset relation holds between two other heads is. That said, oddity is not tantamount to untenability. However, the second problem is that this approach can only work if the Phase Impenetrability Condition (Chomsky 2000) is abandoned. Inverse marking, or more precisely, the features that trigger it, must percolate from $\mathrm{D}$ to demonstratives, relative clause markers (C, on the analysis of Adger, Harbour, and Watkins 2009), and the verbal agreement prefix (Asp, v, and Appl, on the analysis of Adger and Harbour 2007a, Adger, Harbour, and Watkins 2009). According to the Phase Impenetrability Condition, C, Asp, v, and Appl cannot have access to the content of Class and Number, internal to phasal D.

Thus, empirical matters are not improved by resorting to conceptually problematic pseudoprivativity.

\section{Conclusion}

On purely conceptual grounds, privativity is to be preferred over bivalence. However, faced with facts, bivalence is demonstrably superior. It permits an analysis of Kiowa-Tanoan noun classification that

(a) uses only features that are directly semantically motivated;

(b) uses only syntactic mechanisms that are independently required (Carstens 1991, Chomsky 2001);

(c) generates all and only the attested agreement classes; and

(d) explains, in conjunction with the differing inverse conditions (13) and (26), why Kiowa and Jemez have precisely the classes they do.

By contrast, the best of the private analyses, presence $\sim$ absence privativity

(a') requires a conceptually obscure feature [inverse], for purely morphological expedience;

$\left(\mathrm{b}^{\prime}\right)$ uses syntactic mechanisms that violate Inclusivity (to induce inverse marking) and that, qua feature annotation, are formally akin to bivalence ( ${ }^{x}$-notation);

$\left(\mathrm{c}^{\prime}\right)$ generates agreement profiles that no noun in any Kiowa-Tanoan language attests; and

$\left(d^{\prime}\right)$ does not explain the distribution of classes across Kiowa and Jemez.

The conclusion to be drawn is that the atoms of number provided by Universal Grammar are bivalent and that some languages crucially exploit the three-way distinction, $\emptyset \sim[-\mathrm{F}] \sim[+\mathrm{F}]$, that this permits. 


\section{References}

Adger, David. 2006. Remarks on minimalist feature theory and Move. Journal of Linguistics 42:663-674.

Adger, David, and Daniel Harbour. 2007a. Syntax and syncretisms of the Person Case Constraint. Syntax 10:2-37.

Adger, David, and Daniel Harbour. 2007b. Why phi? In Phi theory: Phi-features across modules and interfaces, ed. by Daniel Harbour, David Adger, and Susana Béjar, 1-34. Oxford: Oxford University Press.

Adger, David, Daniel Harbour, and Laurel J. Watkins. 2009. Mirrors and microparameters: Phrase structure beyond free word order. Cambridge: Cambridge University Press.

Béjar, Susana. 2003. Phi-syntax: A theory of agreement. Doctoral dissertation, University of Toronto.

Béjar, Susana, and Milan Rezac. 2009. Cyclic Agree. Linguistic Inquiry 40:35-73.

Borer, Hagit. 2005. Structuring sense: In name only. Oxford: Oxford University Press.

Carstens, Vicki. 1991. The morphology and syntax of determiner phrases in Kiswahili. Doctoral dissertation, UCLA, Los Angeles, CA.

Chierchia, Gennaro. 1998. Plurality of mass nouns and the notion of 'semantic parameter'. In Events and grammar, ed. by Susan Rothstein, 53-103. Dordrecht: Kluwer.

Chomsky, Noam. 2000. Minimalist inquiries: The framework. In Step by step: Essays on minimalist syntax in honor of Howard Lasnik, ed. by Roger Martin, David Michaels, and Juan Uriagereka, 89-115. Cambridge, MA: MIT Press.

Chomsky, Noam. 2001. Derivation by phase. In Ken Hale: A life in language, ed. by Michael Kenstowicz, 1-52. Cambridge, MA: MIT Press.

Chomsky, Noam, and Morris Halle. 1968. The sound pattern of English. New York: Harper and Row. Reprinted: Cambridge, MA: MIT Press (1991).

Corbett, Greville. 2000. Number. Cambridge: Cambridge University Press.

Corbett, Greville. 2005. The canonical approach in typology. In Linguistic diversity and language theories, ed. by Zygmunt Frajzyngier, Adam Hodges, and David S. Rood, 25-49. Amsterdam: John Benjamins.

Cowper, Elizabeth. 2005. A note on number. Linguistic Inquiry 36:441-455.

Cysouw, Michael. 2003. The paradigmatic structure of person marking. Oxford: Oxford University Press.

Dowty, David, and Pauline Jacobson. 1988. Agreement as a semantic phenomenon. In ESCOL '88: Proceedings of the Fifth Eastern States Conference on Linguistics, ed. by John Powers and Franscisca de Jong, 95-101. Ithaca, NY: Cornell University, CLC Publications.

Fodor, Janet. 1977. Semantics: Theories of meaning in generative grammar. New York: Thomas Y. Crowell.

Grimshaw, Jane. 2005. Extended projection. In Words and structure, ed. by Jane Grimshaw, 1-74. Stanford, CA: CSLI Publications.

Hale, Ken. 1997. Some observations on the contribution of local languages to linguistic science. Lingua 100:71-89.

Harbour, Daniel. 2003. The Kiowa case for feature insertion. Natural Language and Linguistic Theory 21: 543-578.

Harbour, Daniel. 2006. Numerus: Der morphologische Gebrauch semantischer Atome (Number: Morphological use of semantic means). Queen Mary's Occasional Papers Advancing Linguistics (OPAL) 5. Available at http://webspace.qmul.ac.uk/dharbour/Queen-Mary's-OPALs.html.

Harbour, Daniel. 2007. Morphosemantic number: From Kiowa noun classes to UG number features. Dordrecht: Springer.

Harbour, Daniel. 2009a. Mass, non-singularity, and augmentation. In Proceedings of the 2007 Workshop in Greek Syntax and Semantics at MIT, ed. by Claire Halpert, Jeremy Hartman, and David Hill, 349-360. MIT Working Papers in Linguistics 57. Cambridge, MA: MIT, MIT Working Papers in Linguistics.

Harbour, Daniel. 2009b. The universal basis of local linguistic exceptionality. Behavioral and Brain Sciences $32: 456-457$. 
Harbour, Daniel. 2011. Descriptive and explanatory markedness. Morphology 21:223-245.

Harley, Heidi, and Elizabeth Ritter. 2002. Person and number in pronouns: A feature-geometric analysis. Language 78:482-526.

Jakobson, Roman, Sergei Karcevsky, and Nikolai Trubetzkoy. 1928. Quelles sont les méthodes les mieux appropriées à un exposé complet et pratique d'une langue quelconque? In Roman Jakobson, Selected writings I, 3-6. 2nd ed. The Hague: Mouton (1971).

Kihm, Alain. 2002. What's in a noun: Noun classes, gender, and nounness. Available at http://www.llf.cnrs .fr/fr/kihm.

Link, Godehard. 1983. The logical analysis of plurals and mass terms: A lattice-theoretical approach. In Meaning, use and interpretation of language, ed. by Rainer Bäuerle, Christoph Schwarze, and Arnim von Stechow, 302-323. Berlin: Walter de Gruyter.

Marantz, Alec. 1997. No escape from syntax: Don't try morphological analysis in the privacy of your own lexicon. In Proceedings of the 21st Annual Penn Linguistics Colloquium, ed. by Alexis Dimitriadis, Laura Siegel, Clarissa Surek-Clark, and Alexander Williams, 201-225. University of Pennsylvania Working Papers in Linguistics 4.2. Philadelphia: University of Pennsylvania, Penn Linguistics Club.

Merrifield, William R. 1959. Classification of Kiowa nouns. International Journal of American Linguistics 25:269-271.

Nevins, Andrew. 2011. Marked targets versus marked triggers and impoverishment of the dual. Linguistic Inquiry 42:413-444.

Noyer, Rolf. 1992. Features, positions and affixes in autonomous morphological structure. Doctoral dissertation, MIT, Cambridge, MA.

Ojeda, Almerindo. 1992. The semantics of number in Arabic. In SALT II: Proceedings of the Second Conference on Semantics and Linguistic Theory, ed. by Chris Barker and David Dowty, 303-325. Columbus: Ohio State University, Department of Linguistics.

Ojeda, Almerindo. 1998. The semantics of collectives and distributives in Papago. Natural Language Semantics 6:245-270.

Ouhalla, Jamal. 2005. Agreement features, agreement and antiagreement. Natural Language and Linguistic Theory 23:655-686.

Partee, Barbara H., and Vladimir Borschev. 2003. Genitives, relational nouns, and argument-modifier ambiguity. In Modifying adjuncts, ed. by Ewald Lang, Claudia Maienborn, and Cathrine Fabricius-Hansen, 67-112. Berlin: Mouton de Gruyter.

Pollard, Carl, and Ivan Sag. 1994. Head-Driven Phrase Structure Grammar. Stanford, CA: CSLI Publications.

Reinhart, Tanya. 2002. The theta system: An overview. Theoretical Linguistics 28:229-290.

Ritter, Elizabeth. 1991. Two functional categories in noun phrases: Evidence from Modern Hebrew. In Perspectives on phrase structure, ed. by Susan Rothstein, 37-62. Syntax and Semantics 26. New York: Academic Press.

Ritter, Elizabeth. 1993. Where's gender? Linguistic Inquiry 24:795-803.

Sauerland, Uli. 2008. On the semantic markedness of phi-features. In Phi theory: Phi-features across modules and interfaces, ed. by Daniel Harbour, David Adger, and Susana Béjar, 57-82. Oxford: Oxford University Press.

Silverstein, Michael. 1986. Hierarchy of features and ergativity. In Features and projections, ed. by Pieter Muysken and Henk van Riemsdijk, 163-232. Dordrecht: Foris. Originally published in Grammatical categories in Australian languages, ed. by R. M. W. Dixon, 112-171. Canberra: Australian Institutes of Aboriginal Studies (1976).

Sprott, Robert W. 1989. An annotated bibliography of Kiowa-Tanoan. In Kansas working papers in linguistics 14, 2:98-113. Lawrence: University of Kansas, Linguistics Graduate Student Association. Available at http://hdl.handle.net/1808/582. 
Sprott, Robert W. 1992. Jemez syntax. Doctoral dissertation, University of Chicago, Chicago, IL.

Takahashi, Junichi. 1984. Case marking in Kiowa: A study in the organization of meaning. Doctoral dissertation, City University of New York.

Tsoulas, George. 2009. On the grammar of number and mass terms in Greek. In Proceedings of the 2007 Workshop in Greek Syntax and Semantics at MIT, ed. by Claire Halpert, Jeremy Hartman, and David Hill, 333-348. MIT Working Papers in Linguistics 57. Cambridge, MA: MIT, MIT Working Papers in Linguistics.

Watkins, Laurel J. 1984. A grammar of Kiowa. With the assistance of Parker McKenzie. Lincoln: University of Nebraska Press.

Yumitani, Yukihiro. 1998. A phonology and morphology of Jemez Towa. Doctoral dissertation, University of Kansas, Lawrence.

Department of Linguistics (SLLF)

Queen Mary University of London

Mile End Road

London E1 4NS

United Kingdom

harbour@alum.mit.edu 